\title{
Electrospun BiOI nano/microtectonic plate-like structure synthesis and UV-light assisted photodegradation of ARS dye $\dagger$
}

\begin{abstract}
Veluru Jagadeesh Babu, ${ }^{\text {*a }}$ R. S. R. Bhavatharini ${ }^{\mathrm{b}}$ and Seeram Ramakrishna*bc
$\mathrm{BiOl}$ electrospun nanofibers were prepared by using PAN as a supporting polymer. Subsequent annealing at $500{ }^{\circ} \mathrm{C}$ for $5 \mathrm{~h}$, with a ramp rate of about $5^{\circ} \mathrm{C} \mathrm{min}^{-1}$ in air, breaks the nanofibers down to tectonic plate-like nano/microstructures. The surface physical and chemical structural changes were then further characterized by FE-SEM, TEM, XRD and XPS. The results reveal that the morphology and crystallite size of $\mathrm{BiOl}$ vary strongly depending on the precursor concentration used in the synthesis method. These nanostructures were later employed for photocatalytic degradation of a synthetic textile dye, Alizarin Red S (ARS). The photocatalytic efficiencies were found to be about $93.34 \%$ after 100 min of UV-light (340 $\mathrm{nm}$ ) illumination. Photocatalytic activity (PCA) performance depends on morphology and band alignment. All the compositions follow first order pseudo-kinetics, which was found to be $0.1197 \mathrm{~min}^{-1}$ for a doping concentration of $3 \%$. The enhancement in photodegradation could be possibly by photocatalysis and a photosensitization phenomenon. This has been explained based on the band edge position.
\end{abstract}

Received 20th January 2014

Accepted 21st February 2014

DOI: $10.1039 / c 4 r a 00579 a$

www.rsc.org/advances

the photogenerated electron-hole $(\mathrm{e} / \mathrm{h})$ pairs caused by static internal electric forces between the $\left[\mathrm{Bi}_{2} \mathrm{O}_{2}\right]^{2+}$ slabs and the anionic halogen layers. ${ }^{9}$ This static internal force can in turn be controlled by carefully choosing the structure and morphology of the materials. Binding forces, crystal morphology, structural anisotropy and synthesis routes are the basic parameters to monitor in design of nanostructures. In this context BiOX show several exotic physicochemical, electrical, magnetic, luminescent, mechanical, photocatalytic, optical and photophysical properties. These properties enable in tuning emission wavelengths and enhancing fluorochrome quantum yields. ${ }^{10,11}$

Among these oxohalides, BiOI has been reported to be an efficient visible light driven photocatalyst, utilized for the degradation of methyl orange, phenol and other well known organic pollutants. ${ }^{12,13}$ The valence band (VB) and conduction band (CB) for BiOI are at $2.39 \mathrm{eV}$, and $0.48 \mathrm{eV}$, respectively. ${ }^{6}$ Hence, the estimated band gap is about $1.91 \mathrm{eV}$, with very strong absorption in the visible light region and results in the best photocatalytic dye degradation. However, due to the quick recombination of the photoexcited charge carriers, the PCA of BiOI is limited. ${ }^{14,15}$ Thus, the photocatalytic reactivity of BiOI must be further enhanced in order to be useful in practical applications. However for effective photodegradation, it is imperative to discover a suitable and simple synthesis technique that enables control of the morphology and thereby its influence on the photocatalytic performance of BiOI.

The objective of this study is to synthesize BiOI nanofibers through electrospinning, which is a simple and efficient technique used for the preparation of 1D-nanomaterials, for the precise control of the diameter of the fibers thus produced. The 
as-spun nanofibers were annealed at $500{ }^{\circ} \mathrm{C}$ for $5 \mathrm{~h}$, with a ramp rate of about $5{ }^{\circ} \mathrm{C} \min ^{-1}$ in air. After the heat treatment, the uniform and smooth electrospun nanostructures were broken down into nanotectonic plate-like structures due to the evaporation of the polymer content. XRD, microscopy, spectroscopy, and photocatalysis studies were carried out on the synthesized samples. The photocatalysis studies revealed that the nanotectonic plate-like structures produced an enhancement in photodegradation towards Alizarin Red S (ARS) dye under UVlight irradiation.

\section{Experimental section}

\section{Materials}

Bismuth(III) iodide (99\%), polyacrylonitrile (PAN, $M_{\mathrm{w}}=150000$ Da), $N, N$-dimethylformamide (DMF) (anhydrous 99.8\%), and Alizarin Red S (ARS) were obtained from Sigma Aldrich Chemical Company, Inc., St. Louis, U.S. All chemicals were used without further purification.

\section{Preparation}

The fiber deposition parameters (flow rate, applied voltage, drum rotation speed, etc.) were optimized until uniform nanofibers were obtained without bead formation. ${ }^{\mathbf{1 6}, \mathbf{1 7}}$ For the preparation of BiOI nanofibers, PAN solution of about $10.0 \mathrm{wt} \%$ was initially prepared by dissolving PAN powder in DMF and was stirred for about 2 hours. After a reasonably miscible solution was obtained, $1 \% \mathrm{BiI}_{3}$ was then added to the as-prepared miscible solution of PAN, followed by vigorous stirring at room temperature for $12 \mathrm{~h}$ to form a homogeneous yellowish solution. This process was then repeated with various concentrations of $\mathrm{BiI}_{3}(2 \%, 3 \%$ and $4 \% \mathrm{w} / \mathrm{v})$ in PAN. The solution was taken in a $10 \mathrm{~mL}$ syringe with a $21 \mathrm{G} 1 / 2$ gauge needle. The flow rate was maintained at $1.0 \mathrm{~mL} \mathrm{~h}^{-1}$ and the distance between the electrodes (tip of the needle to the collector) was maintained at about $10 \mathrm{~cm}$. The applied electrical voltage between the drum collector and the tip of the needle was $20 \mathrm{kV}$ and the humidity level inside the electrospinning chamber was maintained ${ }^{\mathbf{1 8}}$ at approximately $50 \%$ throughout the experiment.

The as-spun material which collected on the aluminium foil was annealed at $500{ }^{\circ} \mathrm{C}$ for $5 \mathrm{~h}$, with a ramp rate of about $5{ }^{\circ} \mathrm{C}$ $\min ^{-1}$ in air. The uniform and continuous nanofibers break down into unique nanostructures (based on the used precursors $)^{\mathbf{1 9 , 2 0}}$ during the sintering process due to the decomposition of PAN. These electrospun nanoplates, converted from the nanofibers, were later vacuum-dried to remove any residual solvent.

\section{Characterization}

Surface characterization was done by field emission scanning electron microscopy (FESEM; Quanta 200F, FEI, Oregon, U.S.) on samples that were previously gold-coated (JEOL JFC-1200 fine coater, Japan). Transmission electron microscopy (TEM) was used to characterize the morphology by a JEOL JEM-2010F transmission electron microscope, operated at an acceleration voltage of $200 \mathrm{kV}$. The crystal structures of BiOI were characterized by X-ray diffraction (XRD) using a PANalytical $\mathrm{X}$ 'Pert Pro multipurpose X-ray diffractometer in the range of $2 \theta$ $=5-80^{\circ}$ with an intensity of CuK $\alpha$ radiation $(1.5418 \AA)$ for the high concentration. X-ray photoelectron spectra were obtained for the elemental study using a Kratos AXIS Ultra DLD spectrometer (Kratos Analytical Ltd., U.K.).

\section{Photocatalytic degradation}

A suspension of the nanofibrous photocatalyst and an aqueous ARS solution was prepared as reported previously. ${ }^{19,20}$ The dye solution was prepared by dissolving $50 \mathrm{mg}$ of ARS powder in 50 $\mathrm{mL}$ of deionized (DI) water. The suspension was ultrasonicated for about $30 \mathrm{~min}$ to obtain a homogeneous solution and establish an adsorption-desorption equilibrium between the organic molecules and the catalyst surface. The initial concentration $\left(C_{\mathrm{o}}\right)$ of the dye was measured before being exposed to the UV-irradiation. Later the dispersion was placed in such a way that it was completely surrounded by the light source (a conventional UV lamp was used as the light source). ${ }^{19}$ Decreases in the concentrations of dyes were analyzed by a Shimadzu UV3600 UV-vis spectrophotometer, (spectral resolution of $1 \mathrm{~nm}$ ). Then, at given intervals of illumination, the samples of the reaction solution were taken out and the absorption spectra were analyzed.

\section{Results and discussion}

\section{Physico-chemical characterization}

Fig. $1\left(a_{1}, b_{1}, c_{1}\right.$ and $\left.d_{1}\right)$ show the SEM images of the as-synthesized electrospun BiOI nanofiber mats at different blend compositions with a fixed total solution concentration of about 10 wt $\%$ PAN solution in DMF.

To obtain smooth, bead-free nanofibers, this content needed to be maintained at $10 \%$. At all considered blend compositions, the nanofibers were found to be uniform and aligned, with slightly rough surfaces. At lower loadings, the fibers seem to be uniform, but with increasing concentrations of iodine, the fibers become smoother and more uniform. Fig. $1\left(a_{2}, b_{2}, c_{2}\right.$, and $\mathrm{d}_{2}$ ) show the SEM micrographs of BiOI, which exhibit a different morphology with the anomalous rough textured nanoplates; the sizes of these rounded nano- and microplates are less than 2 $\mu \mathrm{m}$, and their regular shapes suggest that they are of a crystalline nature. They intersect with each other over various orientations with the surrounding neighbouring nanoplates systematically forming a step-like feature as can be seen in Fig. $1\left(b_{2} \& c_{2}\right)$. As shown in Fig. $1\left(c_{2}\right)$, the overall FESEM image presents a panoramic morphology of the dispersed nanoplates with thicknesses in the range of $400-800 \mathrm{~nm}$, indicating that uniform BiOI "nanotechton"-like structures ${ }^{21}$ can be prepared in high yields by this simple and facile route.

A high resolution TEM image of a single nanotectonic plate/ rod shape is shown in Fig. 2(a). The TEM image reveals that the BiOI tectonic plate is a well-defined longish particle with an average size of $\sim 150$ to $200 \mathrm{~nm}$, confirming the SEM revelations, and suggesting that BiOI tectonics are probably the best morphological structures for photocatalytic reactions. 

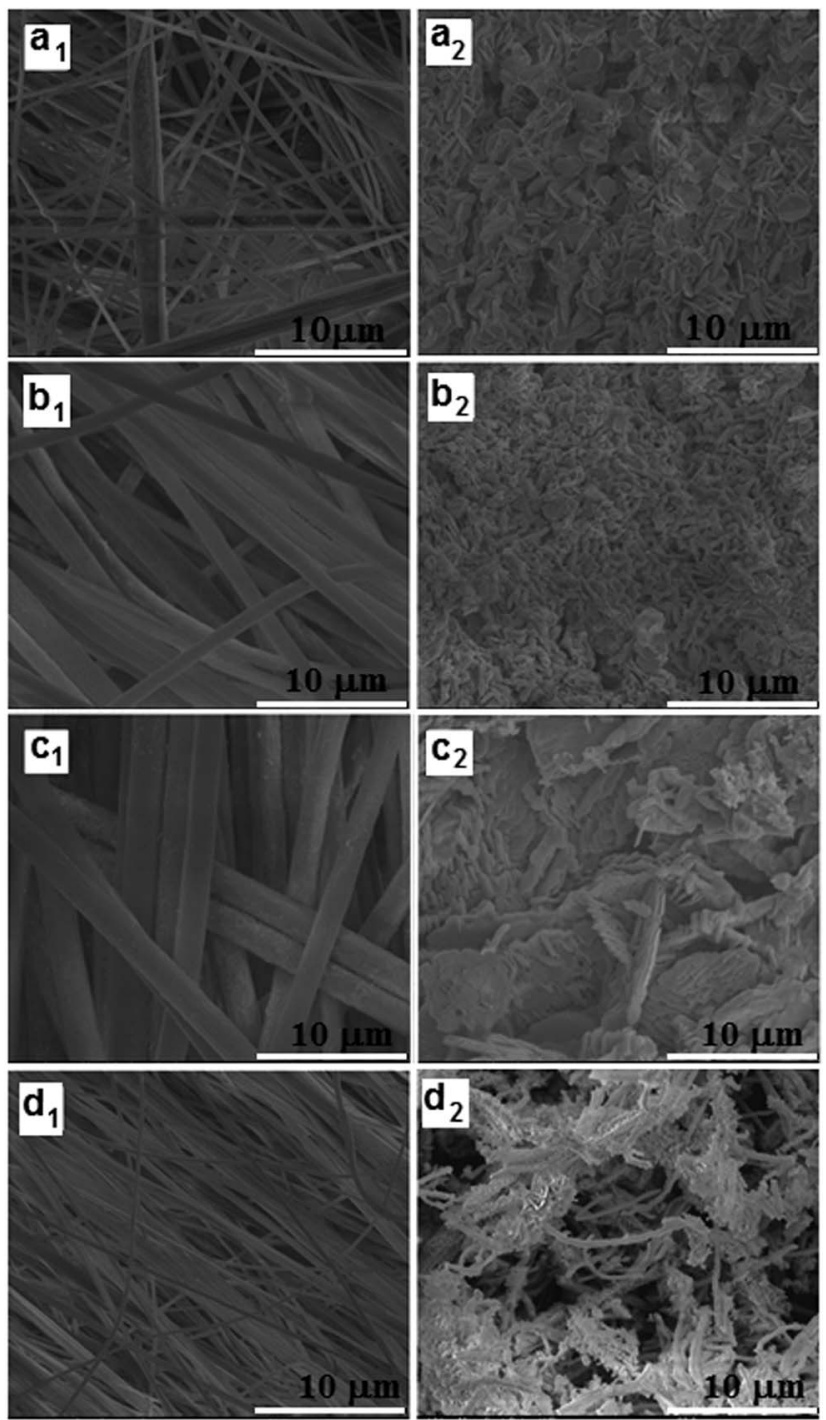

Fig. 1 SEM images of $a_{1}, b_{1}, c_{1}$ and $d_{1}$ as-spun nanofibers and $a_{2}, b_{2}, c_{2}$ and $d_{2}$ sintered $\mathrm{BiOl}$ at concentrations of $1,2,3$, and $4 \%(\mathrm{w} / \mathrm{v})$.

The XRD pattern of the nanotectonic plates is shown in Fig. 2(b). From the XRD pattern, all the peaks have been identified and perfectly indexed related to the BiOI and there are no other peaks for impurities. This reveals that the BiOI produced by electrospinning is of high purity. The average crystalline size, about $\sim 168 \mathrm{~nm}$ at the (001) lattice plane, is calculated from the XRD pattern by using the Scherrer formula $(d=0.94 \lambda)$ $\beta \cos \theta),{ }^{22,23}$ where $d$ is the crystal size, $\lambda$ is the wavelength of the $\mathrm{CuK} \alpha$ radiation, $\beta$ is the FWHH (full width at half height) in radians, and $\theta$ is the Bragg's angle for diffraction peaks.

$\mathrm{X}$-ray photoelectron spectroscopy (XPS) of the BiOI nanostructures is provided in Fig. 3(a). In Fig. 3, Bi, O, I, and $\mathrm{C}$ elements could be seen. It can also be observed that the spin orbit splitting (SOS) peaks of the Bi $4 \mathrm{f}$ level is split into two peaks centred at 165.0 and $160.1 \mathrm{eV}$, which belong to $\mathrm{Bi} 4 \mathrm{f} 5 / 2$ and $\mathrm{Bi} 4 \mathrm{f} 7 / 2$, respectively. Hence, the main chemical states of the elemental $\mathrm{Bi}$ in the samples were proven to be tri-valent $\left(\mathrm{Bi}^{3+}\right)$. The $\mathrm{C} 1 \mathrm{~s}$ peak at $284.8 \mathrm{eV}$, can be attributed to the
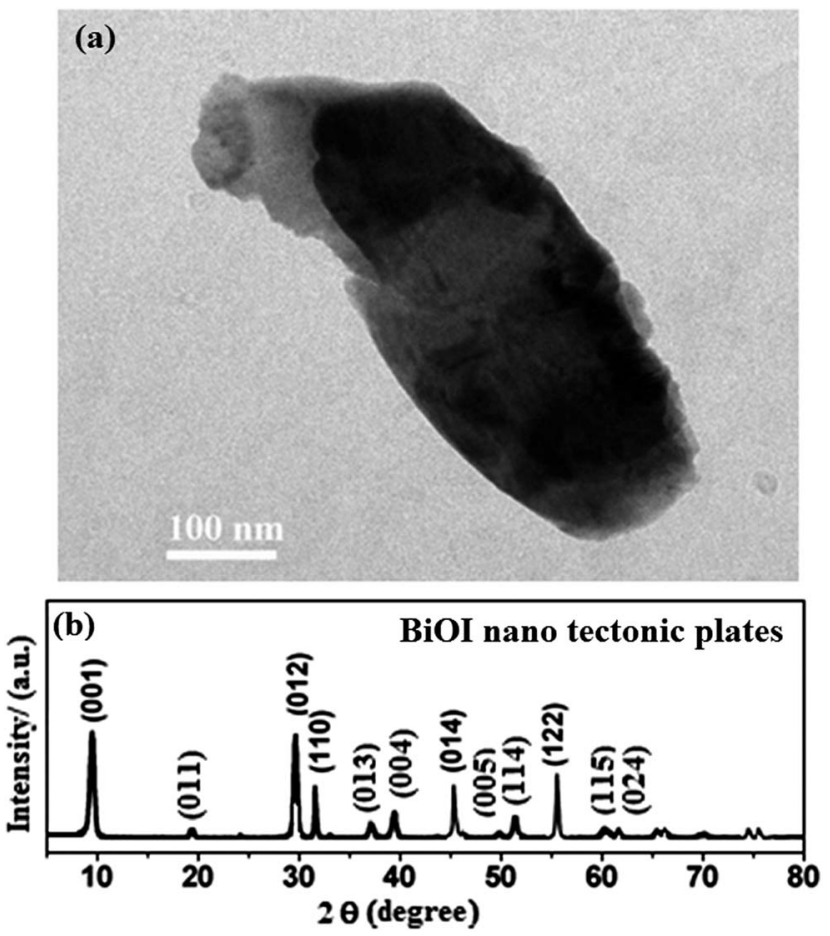

Fig. 2 (a) TEM image of a single BiOl nanotectonic plate-like structure, and (b) XRD patterns obtained on the BiOI nanotectonic plates.

adventitious elemental carbon on the surface of the sample from the experimental conditions. From the survey spectrum, the presence of the $\mathrm{O} 1 \mathrm{~s}$ peak showed a fitted peak near $530 \mathrm{eV}$, which was ascribed to the $\mathrm{Bi}-\mathrm{O}$ bonds in BiOI. ${ }^{23}$

For all the concentrations, there is only one dominating peak at $619.1 \mathrm{eV}$. This peak may be due to $\mathrm{I}^{3-}$ doping of the polymers by the generated iodine. The high-resolution I $3 \mathrm{~d}_{5 / 2}$ spectra are shown in Fig. 3(b). Two very strong peaks are observed at 615.1 of $\mathrm{I} 3 \mathrm{~d}_{5 / 2}$ and at $626.9 \mathrm{eV}$ for $\mathrm{I} 3 \mathrm{~d}_{3 / 2}$ (Fig. 3(b)). These two peaks are the characteristic peaks of $\mathrm{I}^{-}$ within BiOI. Only for a concentration of $4 \%$, two weak shorter peaks were observed at 620.6 and $631.7 \mathrm{eV}$, which may be attributed to the higher loadings of iodine. From these shorter peaks, it can be deduced that iodine atoms get attached via other atoms (probably carbon atoms) and not as pure iodine molecules.

\section{Photodegradation}

The PCA of the BiOI nanotectonic structures was characterized by degrading the quinine dye, ARS, under UV-light irradiation at ambient temperatures. ${ }^{19}$ The temporal evolution of the spectral changes during the photodecomposition of ARS on the sintered BiOI samples under UV-light irradiation is shown in the ESI (SI 1†). A gradual degradation of the dye was observed, but near a wavelength of $240 \mathrm{~nm}$, new peaks started to emerge, showing that there was an occurrence of new products. Photocatalysis studies on the dye without a catalyst were very slow and almost nothing happened for $130 \mathrm{~min}$, whereas, in the presence of a catalyst, the dye was degraded to 

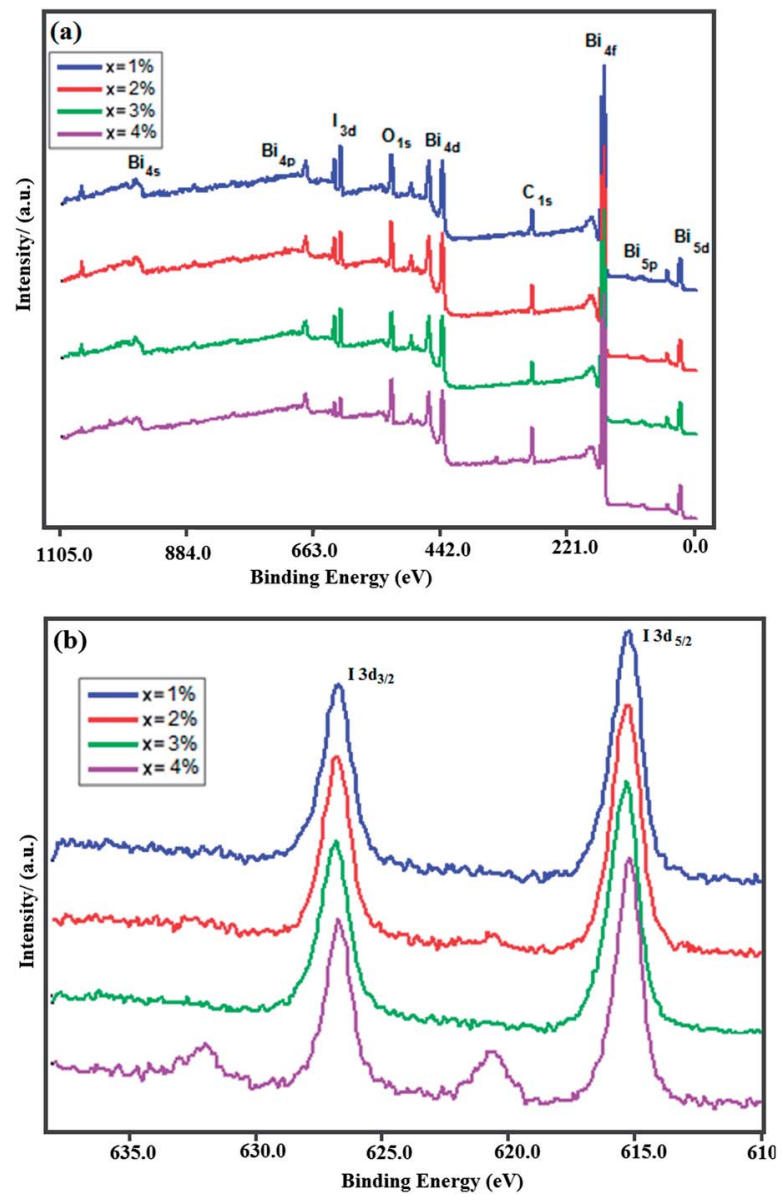

Fig. 3 (a) XPS survey spectra and (b) high resolution XPS I 3d spectra of $\mathrm{BiOl}$ at $1,2,3$, and $4 \%(\mathrm{w} / \mathrm{v})$.

a considerable extent. However, the whole photocatalysis process of the ARS is extremely slow for concentrations at $x=$ 1 and $2 \%$. This may be due to the prolonged exposure of the photocatalyst in an aqueous solution, that leads to the loss of surface iodine, and which further proceeds to form an insulating bismuth hydroxide layer that prevents photochemical activity. ${ }^{12}$ This might explain why there are new peaks at 240 $\mathrm{nm}$ in the absorption spectrum and the photo-electrochemical instability of bismuth oxyiodide in aqueous electrolytes. It has also been reported that semiconductor materials with small band-gaps showed either a low carrier mobility or a low absorption coefficient. ${ }^{24,25}$ Absorption peaks at $518 \mathrm{~nm}$ (shown in the ESI, SI $1 \dagger$ ), were used to monitor the photocatalysis process. The typical absorption peak gradually diminishes markedly with irradiation time and almost completely disappears after $130 \mathrm{~min}$ (due to destruction of the complex structures), ${ }^{26,27}$ suggesting good absorption and photocatalytic activities of the BiOI nano/microtectonic plates. The photocatalysis of ARS is extremely slow without the addition of catalysts, and after addition of catalysts, at a concentration of only $3 \%$ BiOI, ARS was degraded up to $93.34 \%$ within $100 \mathrm{~min}$ under UV-light irradiation. However, the $4 \%$ BiOI samples exhibited limited PCA under similar conditions, indicating that the adsorption equilibrium was reached at a concentration of $3 \%$. Meanwhile, nearly $97 \%$ of the ARS dye was degraded after $130 \mathrm{~min}$ over the as-prepared BiOI photocatalyst (in the case of $1 \%$ and $2 \%$ BiOI), which exhibits efficient PCA under UV-light irradiation. Although, the lower concentrations of BiOI show efficient photocatalytic degradation of a ARS, the photocatalytic efficiencies with respect to time will be poor. The nanostructures (from SEM, Fig. $1\left(\mathrm{~d}_{2}\right)$ ) comprises of fibers and nanoplates, implies the poor absorption and PCA. Since these structures might not be homogeneously distributed all over the ARS dye solution, it is assumed that only dispersion which causes the poor PCA efficiency. In comparison with the nano/microtectonic plates, combined structures (fibers and nanoplates in the case of a concentration of $4 \%$ ) belonging to the priority structure have an unexpectedly (one can also see from the XPS spectra an abrupt peak at $621.3 \mathrm{eV}$ ) poorer absorption property for the ARS dye, which leads to a weaker catalytic effect (Fig. 4).

The nano/microstructures could provide more opportunities for the contact between light and contaminants, resulting in multiple scattering of light. Actually, the photodegradation process is based on electron-hole pairs generated by band gap excitation and has no significant direct correlation with the specific surface area. ${ }^{28}$ The effective separation of light-induced electrons and holes facilitates them to transfer to the surface to react with the absorbed reactants.

The corresponding ARS dye degradation graphs are shown in Fig. 4. Fig. 4 depicts the photodegradation of ARS with and without a catalyst. It is observed that the aqueous solution, with catalysts at different concentrations, and ARS, is effective under UV-illumination. No degradation was observed for ARS over 130 min of UV-irradiation, while the addition of the BiOI catalysts exhibited nearly $94 \%$ degradation of the ARS dye. The unique nanotectonic plate-like structures might be responsible for the excellent photocatalytic performance of BiOI. ARS penetrated into the interlayer and highly porous structures offer many more accessible active sites for the photoreactions. The

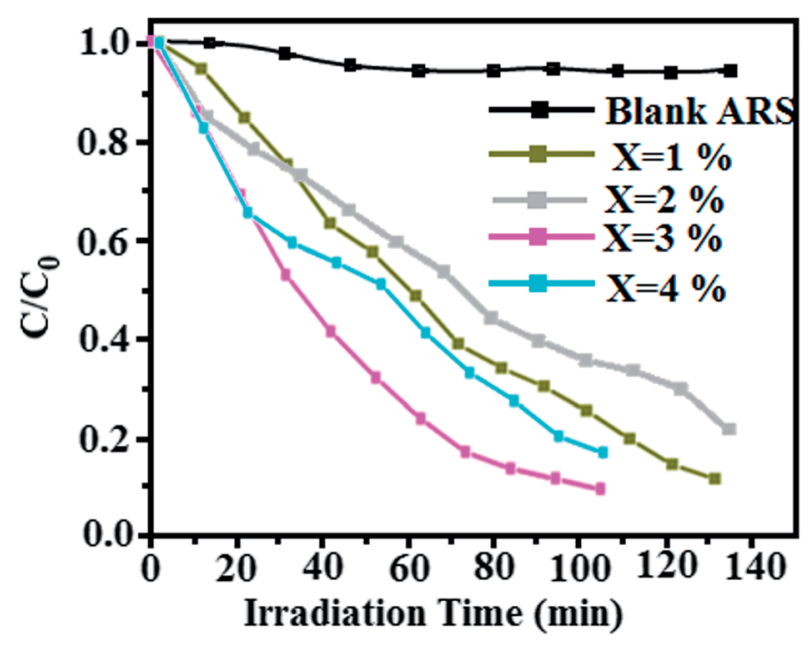

Fig. 4 Photocatalytic reactivity of $\mathrm{BiOI}$ under UV-irradiation for the blank ARS dye and concentrations at $x=1,2,3$, and $4 \%(\mathrm{w} / \mathrm{v})$. 
reactivity rates and photocatalytic efficiencies $(\eta \%)$ were obtained as $0.1124,0.1850,0.0666$, and $0.2865 \mathrm{~min}^{-1} ; 88.76$, $81.49,93.34$, and $71.35 \%$ for $1,2,3$, and $4 \%$ BiOI respectively.

The kinetics of ARS dye degradation over the tectonic plates has been investigated, and is depicted in Fig. 5. The apparent first order kinetic equation was used to elaborate the experimental data. ${ }^{29}$ ARS dye degradation over BiOI fitted well with the first order kinetic equation. The graphs plotted, $\ln \left(c / c_{0}\right)$ as a function of time $(t)$, displayed a straight line fit where $c_{0}$ is the adsorption equilibrium concentration of ARS and $c$ is the concentration of ARS at time ' $t$ '. The calculated kinetic rate constants, $k$, were $0.1666,0.1803,0.1901$, and $0.1197 \mathrm{~min}^{-1}$ for $x$ $=1 \%, 2 \%, 3 \%$ and $4 \%$ respectively. The kinetic rate constant ' $k$ ' value is highest for the BiOI concentration at $x=3 \%$ when compared to the other concentrations.

Fig. 6, clearly indicates the photodegradation mechanism of the ARS dye. Basically, there are two other possible reaction mechanisms involved: photocatalysis ${ }^{30}$ and photosensitization. ${ }^{31}$ For photocatalysis, the degradation of the pure ARS dye occurs without the addition of any catalysts under light illumination with photon energy. The energy of the photon could be transferred from the ARS dye to oxygen, and can act as an oxidizing agent. The resulting photocatalysis of the ARS dye can be seen in eqn (1)-(3). From Fig. 4, one can also observe that the ARS dye could not be degraded by photocatalysis without any added catalysts, even after 130 min of irradiation, suggesting that the ARS dye is stable.

$$
\begin{gathered}
\operatorname{ARS}_{(\text {dye.ads })} \stackrel{h v}{\longrightarrow} \operatorname{ARS}_{(\text {dye.ads })}^{*} \\
\mathrm{ARS}_{(\text {dye.ads) }}^{*}+\mathrm{O}_{2}=2(\mathrm{O})(\text { sunlight })+\mathrm{ARS}_{(\text {dye.ads })} \\
\mathrm{ARS}_{(\text {dye.ads) }}+2(\mathrm{O})(\text { sunlight }) \rightarrow \text { products (see Fig. 6) }
\end{gathered}
$$

The second reaction mechanism is via photosensitization, where the pure ARS dye is adsorbed on the catalyst as a sensitizer. The photogenerated electrons transfer from the valence band (VB) to the conduction band (CB), leaving holes behind
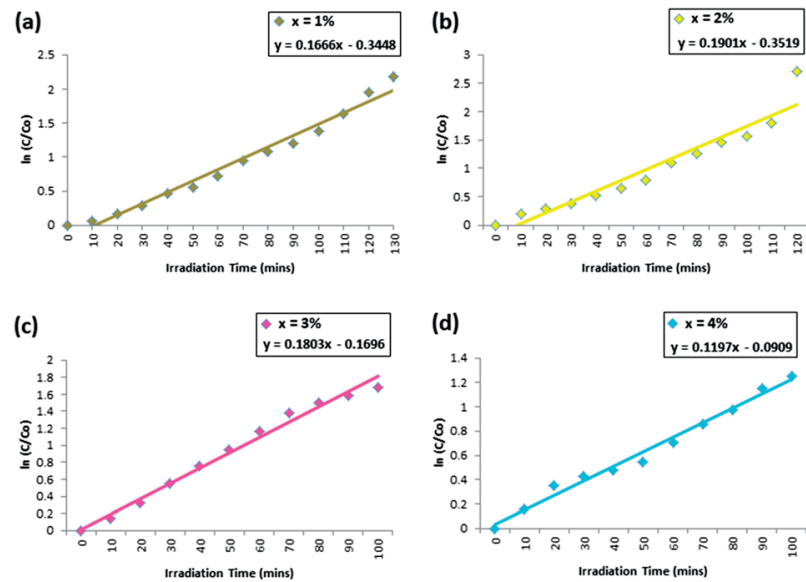

Fig. 5 Kinetic plots and rate constant evaluation of the BiOl photocatalyst at (a) $x=1 \%$, (b) $x=2 \%$, (c) $x=3 \%$ and (d) $x=4 \%(\mathrm{w} / \mathrm{v})$.

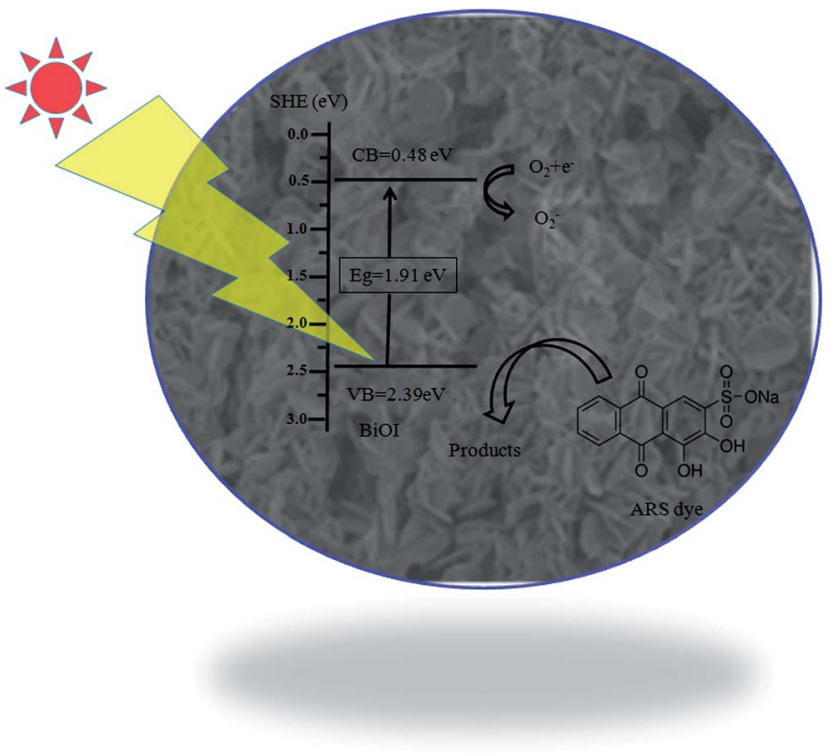

Fig. 6 Schematic representation of ARS dye degradation with BiOI and a diagram of the band edge positions.

the VB top of the ARS dye. Then, the excited electrons react with the oxygen to form oxygen radicals. This is represented in eqn (4)-(6). The generated oxygen radicals and holes can effectively oxidize the dye. The photosensitization reactions are presented in eqn (7)-(10). ${ }^{23}$

$$
\begin{aligned}
& \mathrm{BiOI}_{(\text {catalyst })}+h v \rightarrow \mathrm{h}^{+}+\mathrm{e}^{-} \\
& \mathrm{e}^{-}+\mathrm{O}_{2} \rightarrow \mathrm{O}_{2}^{-} \text {(radical) } \\
& \mathrm{h}^{+}+\mathrm{OH}^{-} \rightarrow \cdot \mathrm{OH} \text { (radical) } \\
& \mathrm{ARS}_{(\text {dye.ads })}^{*}+\mathrm{BiOI}_{(\text {catalyst })} \rightarrow \mathrm{BiOI}_{(\text {catalyst })}\left(\mathrm{e}^{-}\right)+\mathrm{ARS}_{(\text {dye.ads })}{ }^{+}(7) \\
& \mathrm{BiOI}_{(\text {catalyst })}\left(\mathrm{e}^{-}\right)+\mathrm{O}_{2} \rightarrow \mathrm{BiOI}_{(\text {catalyst })}+{ }^{\cdot} \mathrm{O}_{2}{ }^{-} \text {(radical) } \\
& \mathrm{BiOI}_{(\text {catalyst })}+{ }^{\cdot} \mathrm{O}_{2}{ }^{-}+2 \mathrm{H}^{+} \rightarrow \mathrm{BiOI}_{(\text {catalyst })}+2^{\cdot} \mathrm{OH} \text { (radical) (9) } \\
& \mathrm{ARS}_{(\text {dye.ads })}+{ }^{\cdot} \mathrm{O}_{2}{ }^{-} \rightarrow \text { products }
\end{aligned}
$$

Hence, the photodegradation of the ARS dye is initiated to undergo the photocatalysis and photosensitization processes together. The shown enhancement in the photodegradation is due to the electron-hole pair generation, separation and transfer process. Eventually the photosensitization process is largely related to the surface properties and band alignment of the catalyst as shown in Fig. 6. The VB and CB edge positions of BiOI can be evolved from the following formulae (11) and $(12){ }^{23,32,33}$

$$
\begin{gathered}
E_{\mathrm{VB}}=\chi_{(\text {semiconductor })}-E_{\text {(free electrons })}+0.5 E_{\mathrm{g}} \\
E_{\mathrm{CB}}=E_{\mathrm{VB}}-E_{\mathrm{g}}
\end{gathered}
$$

Where $E_{\mathrm{VB}}$ and $E_{\mathrm{CB}}$ are the $\mathrm{VB}$ and $\mathrm{CB}$ band edge potentials respectively, $E_{\mathrm{g}}$ is the band gap energy of a semiconductor, $\chi$ is 
the geometric mean of the electronegativity of the constituent atoms in a semiconductor and $E$ is the energy of free electrons on the standard hydrogen electrode (SHE: $\sim 4.5 \mathrm{eV}$ ). The evolved band edge positions for BiOI are 2.39 and $0.48 \mathrm{eV}$ as the $\mathrm{VB}$ and CB respectively.

\section{Conclusions}

Rounded nano/microtectonic BiOI nanoplates have been synthesized by controlled sintering of electrospinning parameters and precursors. By controlling the synthesis conditions in this study, the precursor concentration facilitates us to tailor the diameters, morphology and thickness of the BiOI plates thus produced. XRD, microscopy, spectroscopy, and photocatalysis studies of the synthesized samples were carried out under UV-vis irradiation. The photocatalysis studies revealed that the nanotectonic plate-like structures exhibited a good PCA towards ARS under UV-light irradiation. However, the ARS dye without any added catalyst (BiOI) exhibited slow photodegradation under UV-light irradiation. The enhancement in photodegradation may be due to effective generation, separation and transfer of electron-hole pairs. Estimated energy band edge positions and possible photodegradation processes have been formulated for the BiOI tectonic plates with the help of previous reports. Hence, the BiOI tectonic plate-like structures are promising for the high photocatalytic degradation of ARS dye.

\section{Acknowledgements}

V. J. Babu, thanks The Scientific \& Technological Research Council of Turkey (TUBITAK) (TUBITAK BIDEB 2221 - Fellowships for Visiting Scientists and Scientists on Sabbatical Leave) for providing a fellowship.

\section{Notes and references}

1 D. Chatterjee and S. Dasgupta, J. Photochem. Photobiol., C, 2005, 6, 186-205.

2 Y. Wang, K. Deng and L. Zhang, J. Phys. Chem. C, 2011, 115, 14300-14308.

3 V. J. Babu, S. Vempati, S. Sundarrajan, M. Sireesha and S. Ramakrishna, Sol. Energy, 2013, DOI: 10.1016/ j.solener.2013.1008.1037.

4 D. L. Dhiman, V. S. Kundu, S. Arora and A. S. Maan, AIP Conf. Proc., 2013, 1512, 598-599.

5 Y.-H. Lei and Z.-X. Chen, J. Chem. Phys., 2013, 138, 054703. 6 X. Xiao, C. Liu, R. Hu, X. Zuo, J. Nan, L. Li and L. Wang, J. Mater. Chem., 2012, 22, 22840-22843.

7 T. B. Li, G. Chen, C. Zhou, Z. Y. Shen, R. C. Jin and J. X. Sun, Dalton Trans., 2011, 40, 6751-6758.

8 P. Kwolek and K. Szacilowski, Electrochim. Acta, 2013, 104, 448-458.
9 H. Zhang, L. Liu and Z. Zhou, Phys. Chem. Chem. Phys., 2012, 14, 1286-1292.

10 L. Zhao, X. Zhang, C. Fan, Z. Liang and P. Han, Phys. B, 2012, 407, 3364-3370.

11 H. Peng, C. K. Chan, S. Meister, X. F. Zhang and Y. Cui, Chem. Mater., 2008, 21, 247-252.

12 N. T. Hahn, S. Hoang, J. L. Self and C. B. Mullins, ACS Nano, 2012, 6, 7712-7722.

13 Y. Li, H. Yao, J. Wang, N. Wang and Z. Li, Mater. Res. Bull., 2011, 46, 292-296.

14 X. Zhang, Z. H. Ai, F. Jia and L. Z. Zhang, J. Phys. Chem. C, 2008, 112, 747-753.

15 X. Zhang, L. Z. Zhang, T. F. Xie and D. J. Wang, J. Phys. Chem. C, 2009, 113, 7371-7378.

16 J. B. Veluru, K. K. Satheesh, D. C. Trivedi, V. R. K. Murthy and T. S. Natarajan, J. Eng. Fibers Fabr., 2007, 2, 25-31.

17 V. J. Babu, V. S. P. Kumar, G. J. Subha, R. V. Kumari, T. S. Natarajan, A. S. Nair and S. Ramakrishna, J. Eng. Fibers Fabr., 2011, 6, 54-59.

18 V. J. Babu, R. P. Rao, A. S. Nair and S. Ramakrishna, J. Appl. Phys., 2011, 110, 064327.

19 V. J. Babu, A. S. Nair, Z. Peining and S. Ramakrishna, Mater. Lett., 2011, 65, 3064-3068.

20 V. J. Babu, M. K. Kumar, A. S. Nair, T. L. Kheng, S. I. Allakhverdiev and S. Ramakrishna, Int. J. Hydrogen Energy, 2012, 37, 8897-8904.

21 Z. Bian, J. Zhu, J. Wang, S. Xiao, C. Nuckolls and H. Li, J. Am. Chem. Soc., 2012, 134, 2325-2331.

22 M. Galceran, M. C. Pujol, C. Zaldo, F. Díaz and M. Aguiló, J. Phys. Chem. C, 2009, 113, 15497-15506.

23 J. Cao, B. Xu, H. Lin, B. Luo and S. Chen, Dalton Trans., 2012, 41, 11482-11490.

24 K. Rajeshwar, J. Appl. Electrochem., 1985, 15, 1-22.

25 Y. Bessekhouad and M. Trari, Int. J. Hydrogen Energy, 2002, 27, 357-362.

26 Y. Li, J. Wang, H. Yao, L. Dang and Z. Li, J. Mol. Catal. A: Chem., 2011, 334, 116-122.

27 K. Ren, K. Zhang, J. Liu, H. Luo, Y. Huang and X. Yu, CrystEngComm, 2012, 14, 4384-4390.

28 A. Rachel, M. Sarakha, M. Subrahmanyam and P. Boule, Appl. Catal., B, 2002, 37, 293-300.

29 J. B. Veluru, K. K. Manippady, M. Rajendiren, K. M. Mya, P. R. Rayavarapu, S. N. Appukuttan, R. Seeram and S. Ramakrishna, Int. J. Hydrogen Energy, 2013, 38, 4324-4333.

30 X. Lin, T. Huang, F. Huang, W. Wang and J. Shi, J. Phys. Chem. B, 2006, 110, 24629-24634.

31 C. Nasr, K. Vinodgopal, L. Fisher, S. Hotchandani, A. K. Chattopadhyay and P. V. Kamat, J. Phys. Chem. B, 2006, 110, 8436-8442.

32 Y. Li, J. Wang, H. Yao, L. Dang and Z. Li, Catal. Commun., 2011, 12, 660-664.

33 Y. Xu and M. A. A. Schoonen, Am. Mineral., 2000, 85, 543556. 